\title{
A DIRECT PROCEDURE FOR THE SEISMIC DESIGN OF FRAME STRUCTURES WITH ADDED VISCOUS DAMPERS
}

\author{
STEFANO SILVESTRI, MICHELE PALERMO \& TOMASO TROMBETTI \\ University of Bologna, Italy.
}

\begin{abstract}
A direct procedure for the seismic design of building structures with added viscous dampers is described in this paper. The procedure is applicable to regular multi-storey frame structures, which are characterized by a period of vibration lower than $1.5 \mathrm{~s}$. It aims at providing practical tools for a direct identification of the mechanical characteristics of the manufactured viscous dampers, which allow to achieve target levels of performances. Typically, the design philosophy is to limit the structural damages under severe earthquakes. In more detail, the procedure may be summarized as follows. First, a target damping reduction factor is selected to achieve a desired reduction in the peak structural response under earthquake excitation. Second, linear damping coefficients are calculated taking advantage of the properties of the modal damping ratios of classically damped systems. Then, analytical formulas allow the estimation of peak velocities and forces in the dissipative devices, and an energy criterion is used to identify the non-linear mechanical characteristics of the actual manufactured viscous dampers. Finally, the internal actions in the structural elements are estimated through the envelope of two equivalent static analyses (ESA), namely: ESA1 in which the naked structure is subjected to a given set of equivalent lateral forces, and ESA2 in which the structure, with rigid diagonal braces substituting the added viscous dampers, is subjected to a top floor lateral force. At this stage of the research, the procedure is suitable for the preliminary design phase, since correction factors for the higher modes contributions are necessary to improve its accuracy, especially for high-rise buildings. A numerical verification of the final behaviour of the system by means of non-linear time-history analyses is recommended. An applicative example is finally provided to highlight the simplicity of the proposed procedure.

Keywords: damping coefficient, five-step procedure, multi-storey frames, seismic design, viscous dampers
\end{abstract}

\section{INTRODUCTION}

For many years the seismic analysis and design of buildings have been carried out using methods based essentially on the concept of equivalent lateral forces. Nowadays, analysis and design procedures are mostly based on the use of non-linear dynamic analyses, which are available in most of common commercial software. The use of dynamic analyses was first introduced in the 1974 by the SEAOC Code [1] for major structures 'with highly irregular shapes, large differences in lateral resistance or stiffness between adjacent storeys'.

As a consequence, when energy dissipation and base isolation systems were first proposed for the mitigation of the seismic effects on the structural elements (1980s), the use of dynamic analyses was already well established as standard practice for the seismic design of building structures. At this point, according to most actual seismic codes (such as the Eurocode 8 [2] or the current Italian Code [3]), structures equipped with added viscous dampers can be analyzed and designed only by means of non-linear dynamic analyses. Indeed, only U.S. building codes (such as the ASCE 7-10 standard [4]) contain specific simplified procedures for analysis and design of buildings with passive energy dissipation systems. These procedures are grounded on the seminal research works carried out in the 1990s at the University at Buffalo [5-8] and summarized in the MCEER-01 report [9]. Nonetheless, none of these well-established procedures have been yet incorporated in Eurocode provisions. 
In the present work, a simplified procedure for the preliminary design of viscous dampers and structural elements of frame structures equipped with inter-storey viscous dampers is presented and exemplified for a three-storey frame building.

\section{THE 'DIRECT FIVE-STEP PROCEDURE'}

\subsection{Procedure overview}

A 'direct five-step procedure', synthetically schematized in the flow chart of Fig. 1a, is here described. It guides the professional engineer through the dimensioning of the nonlinear viscous dampers to be inserted in the frame and the design of the structural members so that a given performance objective is achieved. It integrates some results of previous research works developed by the authors during the last 10 years [10-14]. Even though the procedure is also applicable to yielding frame structures (with an appropriate choice of the overall behaviour factor, see Ref. [13] for details), it is here presented assuming that the frames are designed in order to remain in the elastic phase. Thus, the design philosophy is to limit the structural damages under severe earthquakes.

In its current version, the 'direct five-step procedure' is applicable to regular multi-storey frame structures and to regular prefabricated pendular structures characterized by a period of vibration lower than $1.5 \mathrm{~s}$. For larger periods, correction factors for the higher modes contributions are necessary to improve its accuracy, especially for high-rise buildings. For structures characterised by uniform mass and stiffness along the height and characterised by a period lower than $0.5 \mathrm{~s}$, the procedure leads to conservative estimations of the internal actions in the structural members.

With reference to the seismic response along a given direction of an $N$-storey frame structure with uniform distribution of added viscous dampers along the height of the building, the steps of the procedures can be summarized as follows:

STEP 1: Identification of the performance objective, in terms of: (a) the desired $x \%$ reduction of the base shear due to the presence of the added viscous damper expressed in terms of damping reduction factor: $\eta=1-x / 100$; (b) the equivalent damping ratio $\xi=10 / \eta^{2}-5(\%)$,

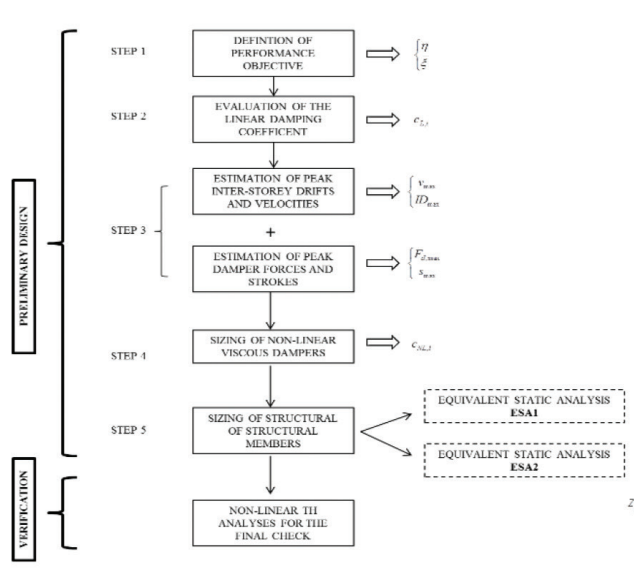

(a)

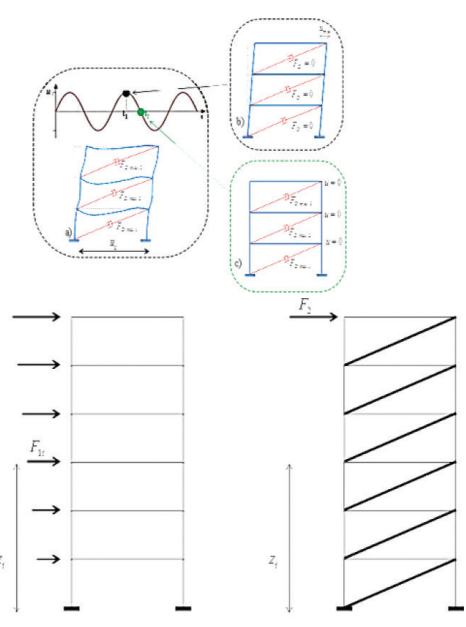

(b)

Figure 1: (a) Flowchart of the proposed design procedure. (b) ESA1 and ESA2 analyses. 
where $\xi=\xi_{i}+\xi_{v}$ is the sum of the inherent damping ( $\xi_{i}$, conventionally set equal to $5 \%$ ) and the viscous damping provided by the added dampers $\left(\xi_{v}\right)$.

STEP 2: Evaluation of the linear damping coefficient $\left(c_{L}\right)$ of the single equivalent viscous damper characterised by a linear force-velocity relationship of the type $F_{d}=c_{L} \cdot \operatorname{sign}(v) \cdot|v|$ (see derivation in Ref. [11]):

$$
c_{L}=\xi \cdot \omega_{1} \cdot m_{t o t} \cdot\left(\frac{N+1}{n}\right) \cdot \frac{1}{\cos ^{2} \theta}
$$

where $\omega_{1}$ is the first mode circular frequency of the structure, $m_{\text {tot }}$ is the total building mass, $N$ is the total number of storeys of the building, $n$ is the total number of dampers placed at each storey in each direction, and $\theta$ indicates the damper inclination with respect to the horizontal line.

STEP 3: Estimations of the peak damper velocity $v_{\max }$, the peak inter-storey drift $I D_{\max }$, the peak damper force $F_{d, \max }$ and the peak damper stroke $s_{\max }$ under the design earthquake $\left(S_{e}\left(T_{1}, \eta\right)\right.$ is the ordinate of the damped pseudo-acceleration elastic response spectrum at the fundamental period of the structure considering the effect of the dampers through factor $\eta$ ) assuming a linear first-mode shape (see derivation in Ref. [14]):

$$
\begin{gathered}
v_{\text {max }}=\frac{S_{e}\left(T_{1}, \eta\right)}{\omega_{1}} \cdot \frac{2}{N+1} \cdot \cos \theta \\
I D_{\max }=\frac{S_{e}\left(T_{1}, \eta\right)}{\omega_{1}^{2}} \cdot \frac{2}{N+1} \\
F_{d, \text { max }}=2 \cdot \xi \cdot m_{t o t} \cdot \frac{S_{e}\left(T_{1}, \eta\right)}{\cos \theta} \\
S_{\max }=\frac{S_{e}\left(T_{1}, \eta\right)}{\omega_{1}^{2}} \cdot \frac{2}{N+1} \cdot \cos \theta
\end{gathered}
$$

STEP 4: Sizing of the 'non-linear' damping coefficient $\left(c_{N L}\right)$ of the commercial damper characterized by a non-linear force-velocity relationship of the type $F_{d}=c_{N L} \cdot \operatorname{sign}(v) \cdot|v|^{\alpha}$ where the $\alpha$ exponent is typically around 0.15 (see derivation in Ref. [11]):

$$
c_{N L}=c_{L} \cdot\left(0.8 \cdot v_{\max }\right)^{1-\alpha}
$$

In order to maintain high efficiency of the device, the axial stiffness $\left(k_{\text {axial }}\right)$ of the dissipative brace(the stiffness due to the compressibility of the oil in the chamber of the damper in series with the stiffness of the supporting brace) should satisfy the following indication [11]:

$$
k_{\text {axial }} \geq 10 \cdot c_{L} \cdot \omega_{1}
$$

STEP 5: Estimation of the internal actions in the structural elements through the envelope of two Equivalent Static Analyses (ESA, Fig. 1b), namely:

- Equivalent Static Analysis 1 (ESA1): the naked structure (e.g. the structure without the added viscous dampers) is subjected to the following set of equivalent lateral forces, with $F_{i}$ indicating the lateral force to apply at the $i$-th floor:

$$
F_{i}=m_{t o t} \cdot S_{e}\left(T_{1}, \eta\right) \cdot \frac{z_{i} \cdot W_{i}}{\sum_{j=1}^{N} z_{j} \cdot W_{j}}
$$


where $W_{i}$ is the seismic weight of the $i$-th floor; the distribution of the lateral forces relates directly to the assumed fist-mode shape.

- Equivalent Static Analysis 2 (ESA2): the structure with rigid diagonal braces substituting the added viscous dampers is subjected to a top-storey lateral force:

$$
F_{\text {top-storey }}=0.8^{1-\alpha} \cdot 2 \cdot \xi \cdot m_{\text {tot }} \cdot \frac{S_{e}\left(T_{1}, \eta\right)}{n}
$$

The application of a lateral force at the roof level only relates to the assumed first-mode shape and leads to the following estimation of the maximum axial force in the columns:

$$
P_{\mathrm{i}, \max }=(N-i+1) \cdot 0.8^{1-\alpha} \cdot 2 \cdot \xi \cdot m_{t o t} \cdot \frac{S_{e}\left(T_{1}, \eta\right)}{n} \cdot \tan \theta
$$

Finally, non-linear time-history analyses are recommended to verify the actual behaviour of the structure and to bring little adjustments to the size of dampers and structural elements.

\subsection{The rationale behind the Equivalent Static Analyses}

During an earthquake, the internal actions in the structural members (such as columns and beams) achieve their maximum values at the instant of maximum lateral displacement. On the other hand, the damper forces are maximized at the instant of maximum inter-storey velocity (approximately coincident with the instant of zero lateral deformation). In case of diagonal dampers placed between two adjacent storeys (inter-storey placement), the forces exerted by the dampers transfer additional axial forces in columns and beams, which in some cases (see section 3) may govern the structural member sizing. For this reason, the maximum internal actions in the structural members can be estimated from the envelope of two following two equivalent static analyses:

- ESA1 is the static analysis of the naked structure subjected to a set of lateral forces producing the same lateral displacements as those developed at the instant of maximum lateral deformation.

- ESA2 is the static analysis of an appropriate structure schematization (e.g. the structure with diagonal rigid bracings replacing the diagonal viscous dampers) which provides the same axial forces in the structural members as those developed at the instant of maximum lateral velocity.

\section{DISCUSSION}

Figure 2 displays the base shear $V_{b a s e}$, the maximum damper force $F_{d, \max }$ and the maximum axial force at the ground floor $P_{\text {base }}=P_{1, \max }$ as a function of the damping ratio, as obtained according to the predictive formulas of the direct five-step procedure (the cases of a 5-storey and 10-storey buildings are considered). The curves are normalized with respect to the base shear of the naked structure $\left(V_{b a s e, \xi=5 \%}\right)$. As expected, with increasing damping ratio, the base shear $V_{\text {base }}$ decreases at the expense of an increase in $F_{d \text {,max }}$ and $P_{b a s e}$. It can be noted that the curves of $V_{\text {base }}$ (blue curve) and $F_{d, \max }$ (red curve) intersect at a $\xi$ value of around 0.35 . With increasing the total number of storeys, $P_{\text {base }}$ increases as well and may become significantly large (for the 10-storey building even 4 times larger than $V_{\text {base, } \xi=5 \%}$ for $\xi \cong 0.35$ ). 


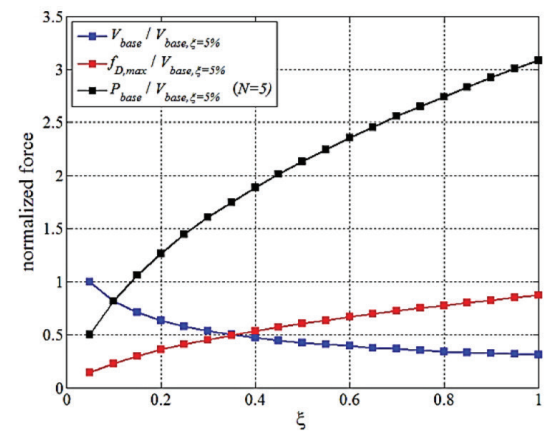

(a-)

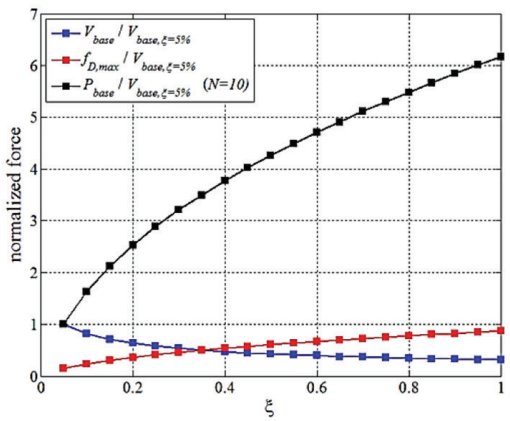

(b)

Figure 2: Base shear, maximum damper force and base axial force: (a) $N=5$, (b) $N=10$.

It is of practical interest to evaluate the necessary amount of damper forces to obtain a target reduction in the base shear $\left(\Delta V_{\text {base }}=V_{\text {base }, \xi=5 \%}-V_{\text {base }}\right)$. By making use of eqn (4), it is possible to express directly the normalized versions of the maximum damper force as a function of the damping reduction factor:

$$
\begin{aligned}
& \frac{F_{d, \max }}{V_{b a s e, \xi=5 \%}}=2 \frac{\left(10-5 \eta^{2}\right)}{\eta \cdot \cos \theta} \\
& \frac{F_{d, \max }}{\Delta V_{\text {base }}}=2 \frac{\left(10-5 \eta^{2}\right)}{(1-\eta) \eta \cos \theta}
\end{aligned}
$$

Figure 3 displays $\frac{F_{d, \text { max }}}{V_{b a s e, \xi=5 \%}}$ versus $\eta$, and $\frac{F_{d, \text { max }}}{\Delta V_{\text {base }}}$ versus $1-\eta$, respectively (for the case of $\theta=45^{\circ}$ ). In detail, Fig. 3a illustrates the cost (in terms of maximum damper force normalized with respect to $V_{\text {base }, \xi 5 \%}$ ) of achieving a prescribed performance (in terms of damping reduction factor $\eta$ ). Figure $3 \mathrm{~b}$ illustrates the cost/benefit ratio (i.e. maximum damper force

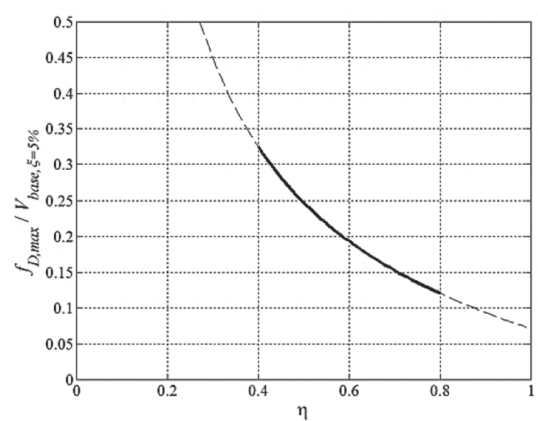

(a)

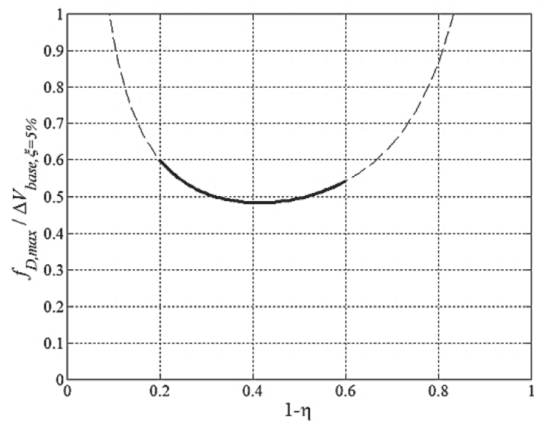

(b)

Figure 3: (a) $\frac{F_{d, \max }}{V_{\text {base }, \xi=5 \%}}$ vs. $\eta$; (b) $\frac{F_{d, \text { max }}}{\Delta V_{\text {base }}}$ vs. $1-\eta$. 
normalized with respect to $\Delta V_{\text {base }}$ ) corresponding to a prescribed reduction in the response parameter (i.e. $1-\eta)$ ). For $1-\eta$ between 0.15 and 0.7 (e.g. $\eta$ between 0.3 and 0.85 , covering the range of added damping ratios between $10-30 \%$ ), the ratio $\frac{F_{d, \max }}{\Delta V_{\text {base }}}$ is less than 1.0, which means that the benefit in terms of reduction of base shear is superior than the cost expressed by the maximum damper force.

\section{APPLICATIVE EXAMPLE}

The applicative example is referred to a 3-storey school building located in Bisignano (CS) in the Calabria region (Southern Italy). The reinforced-concrete frame structure has a $21.4 \mathrm{~m} \mathrm{x} 15 \mathrm{~m}$ rectangular plan (Fig. 4a). The total height of the building is $9.9 \mathrm{~m}$ and the three inter-storey heights are around $3.3 \mathrm{~m}$ (Fig. 4b). The first two floors are school areas where people may congregate (live load $3 \mathrm{kN} / \mathrm{m}^{2}$ ), while the third level represents an impracticable low attic and the roof (live and snow loads to to be not combined with the earthquake action, i.e. $\Psi_{2}=0$ ). The regular structural mesh is composed of four main frames placed along the longitudinal direction, each one characterized by five columns. The columns have $50 \mathrm{~cm} \times 40 \mathrm{~cm}$ cross-section, whilst the longitudinal beams have $40 \mathrm{~cm} \times 60 \mathrm{~cm}$ cross-section at each level. The main longitudinal frames are connected along the perimeter by $50 \mathrm{~cm} \times 40 \mathrm{~cm}$ transversal beams.

Experimental tests on the materials have been carried out. The concrete is characterized by an average cubic compression strength around $R_{c m}=24.6 \mathrm{MPa}$, by a secant elastic modulus equal to $E_{c, s e c}=25000 \mathrm{MPa}$, and density mass of about $2500 \mathrm{~kg} / \mathrm{m}^{3}$. The average yielding strength of the reinforcement bar steel is equal to $f_{y m}=315 \mathrm{MPa}$.

Table 1 presents the load analysis for each floor. The masonry infills weight has been estimated equal to $4.00 \mathrm{kN} / \mathrm{m}^{2}$. The total weight of the building in seismic conditions is equal to $W_{\text {tot }}=11900 \mathrm{kN}$.

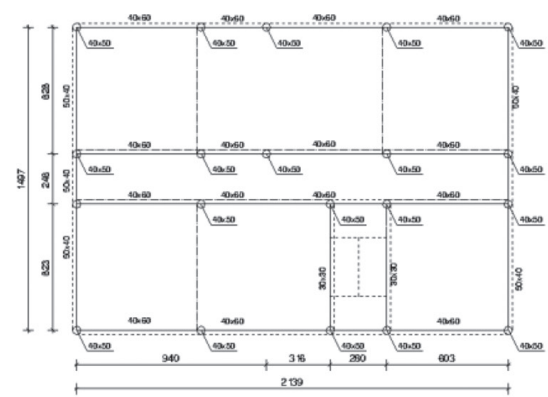

(a)

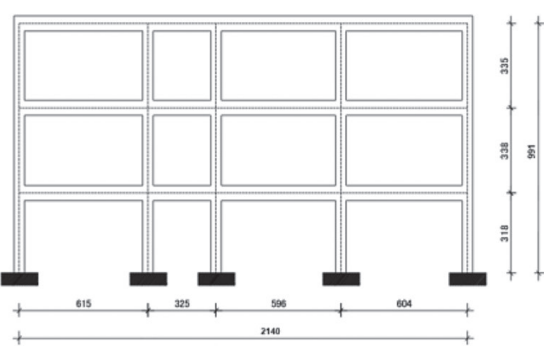

(b)

Figure 4: (a) Building plan. (b) Longitudinal section of the structure.

Table 1: Load analysis.

\begin{tabular}{llll}
\hline Loads & Floor 1 & Floor 2 & Floor 3 (attic + roof) \\
\hline Permanent $G 1$ & $3.00 \mathrm{kN} / \mathrm{m}^{2}$ & $3.00 \mathrm{kN} / \mathrm{m}^{2}$ & $4.00 \mathrm{kN} / \mathrm{m}^{2}$ \\
Permanent $G 2$ & $2.00 \mathrm{kN} / \mathrm{m}^{2}$ & $2.00 \mathrm{kN} / \mathrm{m}^{2}$ & $3.00 \mathrm{kN} / \mathrm{m}^{2}$ \\
Imposed Loads $Q$ & $3.00 \mathrm{kN} / \mathrm{m}^{2}$ & $3.00 \mathrm{kN} / \mathrm{m}^{2}$ & $2.50 \mathrm{kN} / \mathrm{m}^{2}$ \\
& $\left(\Psi_{2}=0.6\right)$ & $\left(\Psi_{2}=0.6\right)$ & $\left(\Psi_{2}=0\right)$ \\
TOTAL in static conditions & $8.00 \mathrm{kN} / \mathrm{m}^{2}$ & $8.00 \mathrm{kN} / \mathrm{m}^{2}$ & $9.50 \mathrm{kN} / \mathrm{m}^{2}$ \\
TOTAL in seismic conditions & $6.80 \mathrm{kN} / \mathrm{m}^{2}$ & $6.80 \mathrm{kN} / \mathrm{m}^{2}$ & $7.00 \mathrm{kN} / \mathrm{m}^{2}$ \\
\hline
\end{tabular}


The frame structure is not capable of supporting the design 712 years-return period peak ground acceleration $\left(a_{g} \cdot S=0.323 g \cdot 1.23=0.40 g\right)$ of the Italian Code [3] provided for school buildings in the site of Bisignano. For the non-linear dynamic analyses, seven artificial accelerograms have been generated so as to match the elastic response spectrum shown in Fig. 5.

The three-dimensional Finite Element (FE) model of the structure is shown in Fig. 6.

Inter-storey viscous dampers have been added along the two main directions of the structure with the aim of keeping the structural elements (columns and beams) within the elastic phase by increasing the structural dissipative properties. In particular, the dampers have been positioned along the perimetrical frames in correspondence of the four corners of the building to reduce the plan rotational response and to obtain a symmetric configuration, as illustrated in Fig. 7.

The modal analysis of the FE model leads to the following results. Due to the absence of transversal beams, the first mode (fundamental mode along the transversal direction) is characterized by a period of vibration significantly larger $(0.80 \mathrm{~s})$ than the one $(0.45 \mathrm{~s})$ of the third mode (fundamental mode along the longitudinal direction). The second mode is characterized by a period equal to $0.52 \mathrm{~s}$ and is purely rotational. The first three modes excite more than $85 \%$ of the total mass of the building along both directions.

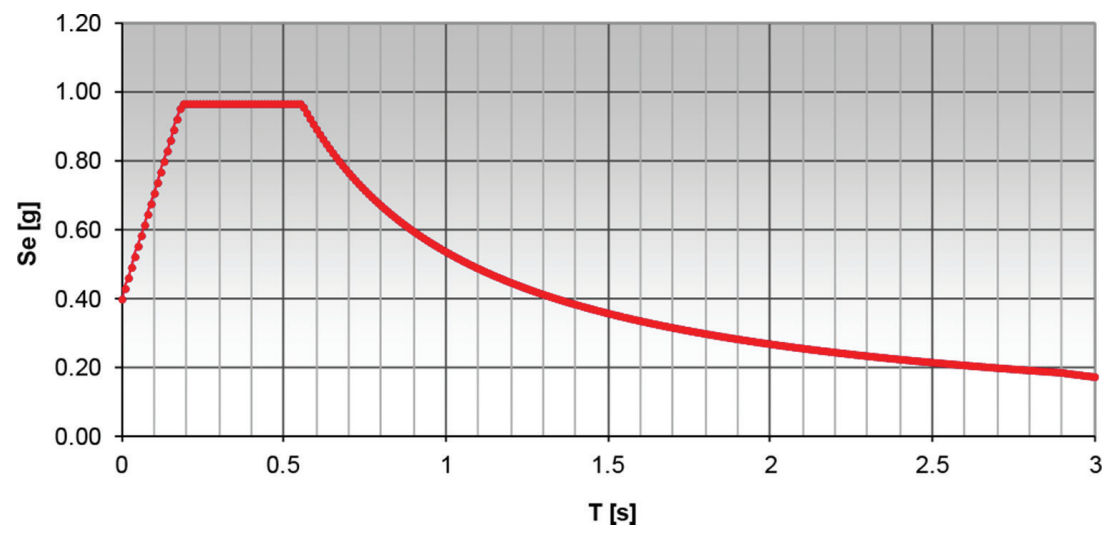

Figure 5: The horizontal pseudo-acceleration elastic response spectrum.

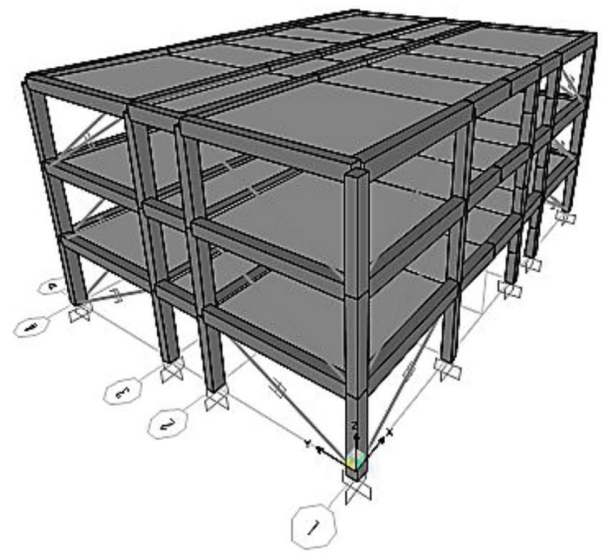

Figure 6: The FE model of the structure. 


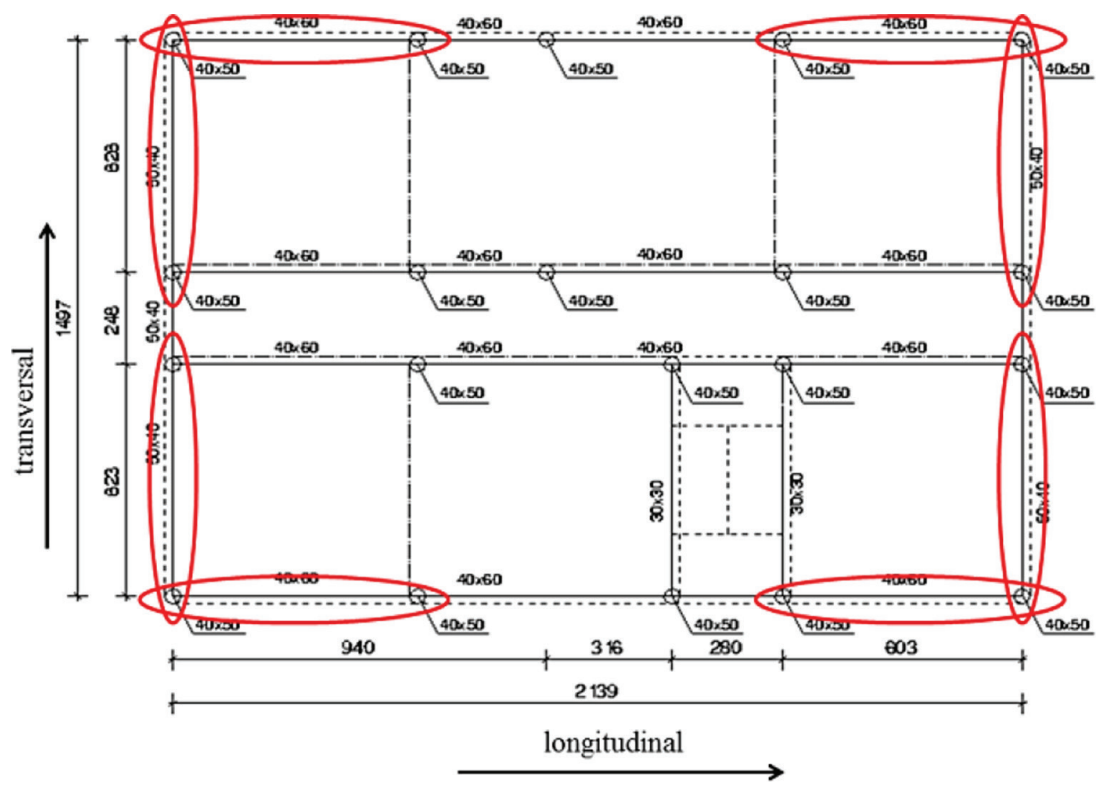

Figure 7: Plan distribution of the viscous dampers.

Since the difference in the periods of vibration along the two main directions is significant, the dimensioning of the viscous dampers should be carried out separately along the two directions. As illustrative example, for sake of conciseness, only the calculations necessary to the sizing of the dampers along the longitudinal direction are reported hereafter.

\section{STEP 1}

Assumed target damping ratio: $\xi=0.30$

Corresponding damping reduction factor: $\eta=\sqrt{\frac{10}{5+\xi}}=\sqrt{\frac{10}{5+30}}=0.53$

Fundamental period along the considered (longitudinal) direction: $T_{1}=0.45 \mathrm{~s}$

Spectral acceleration [3]: $S_{e}\left(T_{1}, \eta\right)=a_{g} \cdot S \cdot \eta \cdot F_{o}=0.323 g \cdot 1.23 \cdot 0.53 \cdot 2.43=0.52 g$

\section{STEP 2}

Number of dampers per floor placed along the longitudinal direction: $n=4$

Damper inclination with respect to the horizontal line: $\theta=27^{\circ}$

Linear damping coefficient, as per eqn (1):

$$
c_{L}=\xi \cdot \omega_{1} \cdot \frac{W_{t o t}}{g} \cdot\left(\frac{N+1}{n}\right) \frac{1}{\cos ^{2} \theta}=0.30 \cdot \frac{2 \pi}{0.45 \mathrm{~s}} \cdot \frac{11900 \mathrm{kN}}{9.81 \frac{\mathrm{m}}{\mathrm{s}^{2}}} \cdot\left(\frac{3+1}{4}\right) \cdot \frac{1}{\cos ^{2} 27^{\circ}} \cong 6400 \frac{\mathrm{kN} \cdot \mathrm{s}}{\mathrm{m}}
$$

\section{STEP 3}

Peak damper velocity estimation for the equivalent linear damper, as per eqn (2):

$$
v_{\max }=\frac{S_{e}\left(T_{1}, \eta\right)}{\omega_{1}} \cdot \frac{2}{N+1} \cdot \cos \theta=\frac{0.52 \cdot 9.81 \frac{\mathrm{m}}{\mathrm{s}^{2}}}{\left(\frac{2 \pi}{0.45 \mathrm{~s}}\right)} \cdot \frac{2}{3+1} \cdot \cos \theta \cong 0.16 \frac{\mathrm{m}}{\mathrm{s}}
$$


Peak damper force estimation for the equivalent linear damper, as per eqn (4):

$$
F_{d, \text { max }}=2 \cdot \xi \cdot \frac{W}{g} \cdot \frac{S_{e}\left(T_{1}, \eta\right)}{n \cdot \cos \theta}=2 \cdot 0.30 \cdot \frac{11900 \mathrm{kN}}{g} \cdot \frac{(0.323 g \cdot 1.23 \cdot 0.53 \cdot 2.43)}{4 \cdot \cos 27^{\circ}}=1025 \mathrm{kN}
$$

Peak damper stroke estimation for the equivalent linear damper, as per eqn (5):

$$
S_{\max }=\frac{S_{e}\left(T_{1}, \eta\right)}{\omega_{1}^{2}} \cdot \frac{2}{N+1} \cdot \cos \theta=\frac{\left(0.323 \cdot 981 \frac{\mathrm{cm}}{\mathrm{s}^{2}} \cdot 1.23 \cdot 0.53 \cdot 2.43\right)}{\left(\frac{2 \pi}{0.45 \mathrm{~s}}\right)^{2}} \cdot \frac{2}{3+1} \cdot \cos 27^{\circ} \cong 1.15 \mathrm{~cm}
$$

STEP 4

$\alpha$-exponent of the commercial damper: $\alpha=0.15$

Non-linear damping coefficient of the commercial damper, as per eqn (6):

$$
c_{N L}=c_{L} \cdot\left(0.8 \cdot v_{\max }\right)^{1-\alpha}=6400 \frac{\mathrm{kN} \cdot \mathrm{s}}{\mathrm{m}} \cdot\left(0.8 \cdot 0.16 \frac{\mathrm{m}}{\mathrm{s}}\right)^{1-0.15} \cong 1115 \frac{\mathrm{kN} \cdot \mathrm{s}^{0.15}}{\mathrm{~m}^{0.15}}
$$

Minimum axial stiffness of the device (non-linear damper + supporting brace), as per eqn (7):

$$
k_{\text {axial }} \geq 10 \cdot c_{L} \cdot \omega_{1}=10 \cdot 6400 \frac{\mathrm{kN} \cdot \mathrm{s}}{\mathrm{m}} \cdot \frac{2 \pi}{0.45 \mathrm{~s}}=8.93 \cdot 10^{5} \frac{\mathrm{kN}}{\mathrm{m}}
$$

Peak damper force estimation for the 'non-linear' damper:

$$
F_{d, \max , N L}=0.8^{1-\alpha} \cdot F_{d, \max }=0.8^{1-0.15} \cdot 1025 \mathrm{kN} \cong 848 \mathrm{kN}
$$

STEP 5

ESA1 analysis:

Lateral forces to be applied at each floor for the whole structure, as per eqn (8):

$$
\begin{aligned}
& F_{h}=\frac{W_{\text {tot }}}{g} \cdot S_{e}\left(T_{1}, \eta\right)=\frac{11900 \mathrm{kN}}{g} \cdot(0.323 g \cdot 1.23 \cdot 0.53 \cdot 2.43) \cong 6090 \mathrm{kN} \\
& F_{1}=F_{h} \cdot \frac{z_{1} \cdot W_{1}}{\sum_{j=1,2, \ldots, N} z_{j} \cdot W_{j}}=6090 \mathrm{kN} \cdot \frac{3.18 \mathrm{~m} \cdot 3928 \mathrm{kN}}{(3.18 \mathrm{~m} \cdot 3928 \mathrm{kN}+6.56 \mathrm{~m} \cdot 3928 \mathrm{kN}+9.91 \mathrm{~m} \cdot 4044 \mathrm{kN})} \\
& \cong 6090 \mathrm{kN} \cdot 0.16=975 \mathrm{kN} \\
& F_{2}=F_{h} \cdot \frac{z_{2} \cdot W_{2}}{\sum_{j=1,2, \ldots, N} z_{j} \cdot W_{j}}=6090 \mathrm{kN} \cdot \frac{6.56 \mathrm{~m} \cdot 3928 \mathrm{kN}}{(3.18 \mathrm{~m} \cdot 3928 \mathrm{kN}+6.56 \mathrm{~m} \cdot 3928 \mathrm{kN}+9.91 \mathrm{~m} \cdot 4044 \mathrm{kN})} \\
& \cong 6090 \mathrm{kN} \cdot 0.33=2016 \mathrm{kN} \\
& F_{3}=F_{h} \cdot \frac{z_{3} \cdot W_{3}}{\sum_{j=1,2, \ldots, N} z_{j} \cdot W_{j}}=6090 \mathrm{kN} \cdot \frac{9.91 \mathrm{~m} \cdot 4044 \mathrm{kN}}{(3.18 \mathrm{~m} \cdot 3928 \mathrm{kN}+6.56 \mathrm{~m} \cdot 3928 \mathrm{kN}+9.91 \mathrm{~m} \cdot 4044 \mathrm{kN})} \\
& \cong 6090 \mathrm{kN} \cdot 0.51=3116 \mathrm{kN}
\end{aligned}
$$


Assuming that each floor is infinitely stiff in its own plane and considering that the four longitudinal frames are equal to each other, the storey forces are evenly distributed along the four frames. Thus, with reference to a single longitudinal frame, Fig. 8 illustrates the static scheme to be solved for ESA1 to obtain the maximum bending moments and shear forces in the structural elements (columns and beams).

ESA2 analysis:

Lateral force to be applied at the roof level for each single frame in which the dampers are present, as per eqn (9):

$$
\begin{aligned}
F_{\text {top-storey }} & =0.8^{1-\alpha} \cdot 2 \cdot \xi \cdot m_{\text {tot }} \cdot \frac{S_{e}\left(T_{1}, \eta\right)}{n}= \\
& =0.8^{1-0.15} \cdot 2 \cdot 0.30 \cdot \frac{11900 \mathrm{kN}}{g} \cdot \frac{(0.323 \cdot g \cdot 1.23 \cdot 0.53 \cdot 2.43)}{4}=756 \mathrm{kN}
\end{aligned}
$$

With reference to one of the two perimetrical frames, Fig. 9 illustrates the static scheme (in which dampers are replaced by rigid braces) to be solved for ESA2 to obtain the maximum axial forces in the columns.

Estimated maximum axial force at the base $(i=1)$ of columns B and D, as per eqn (10):

$$
\begin{aligned}
P_{\text {base }}=P_{1, \max } & =N \cdot 0.8^{1-a} \cdot 2 \cdot \xi \cdot m_{t o t} \cdot \frac{S_{e}\left(T_{1}, \eta\right)}{n} \cdot \tan \theta= \\
& =3 \cdot 0.8^{1-0.15} \cdot 2 \cdot 0.30 \cdot \frac{11900 \mathrm{kN}}{g} \cdot \frac{(0.323 \cdot g \cdot 1.23 \cdot 0.53 \cdot 2.43)}{4} \cdot \tan 27^{\circ}=1155 \mathrm{kN}
\end{aligned}
$$

It is recommended that, after this preliminary dimensioning of the viscous dampers and the structural elements, with the aim of verifying the obtained seismic performances (e.g. the achieved value of $\eta$ ) and of bringing the convenient adjustments, non-linear time-history dynamic analyses are performed to check the actual seismic behaviour of the structure under earthquake ground motions.

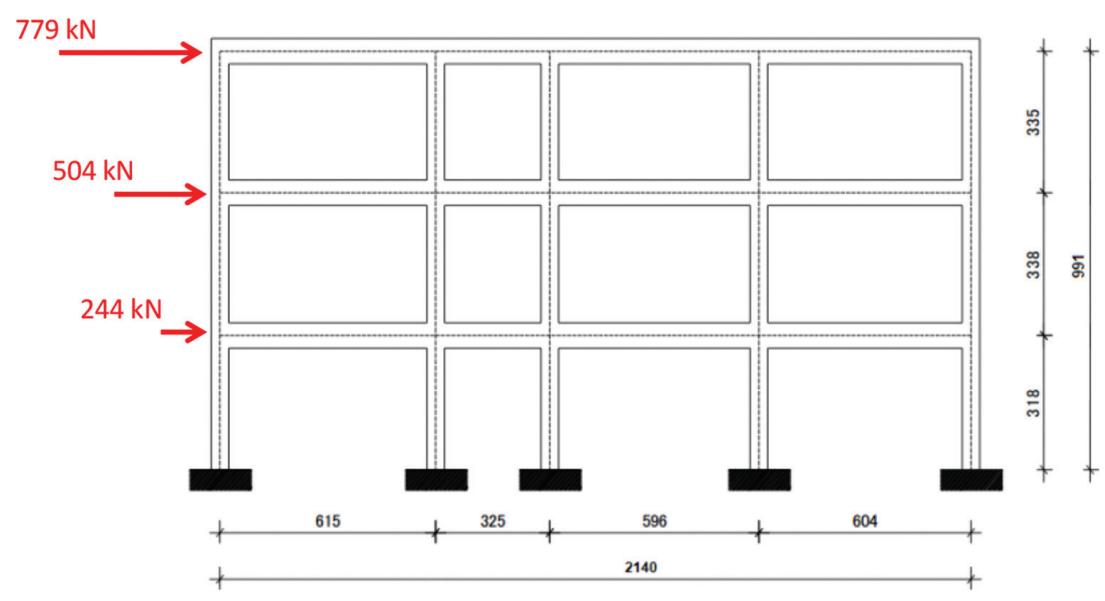

Figure 8: Static scheme to be solved for ESA1. 


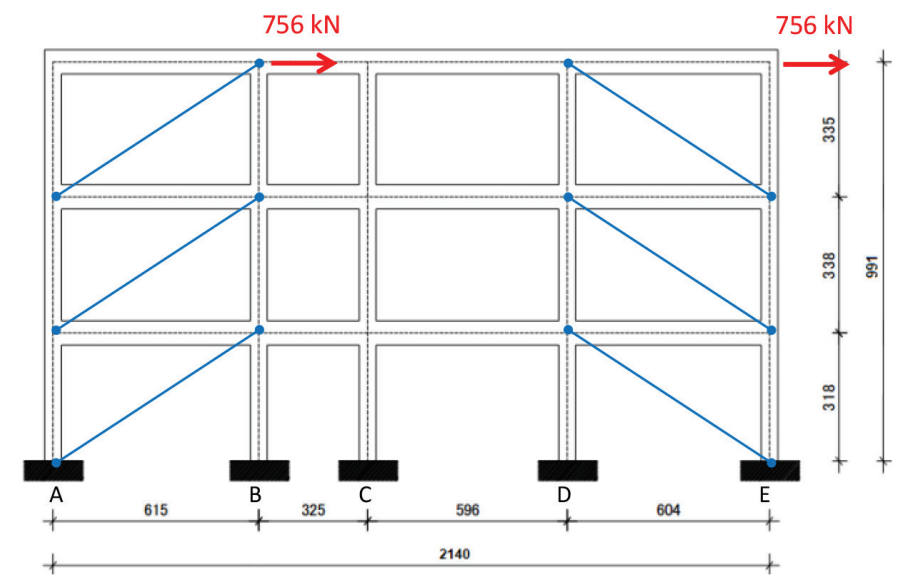

Figure 9: Static scheme to be solved for ESA1.

\section{CONCLUSIONS}

A direct design procedure for frame buildings equipped with inter-storey viscous dampers has been presented. The procedure is aimed at guiding the structural engineer from the choice and sizing of the added viscous dampers to the dimensioning of the structural elements. It allows to obtain analytical estimations/predictions of peak displacements, peak inter-storey drifts and velocities, maximum forces in the dampers and maximum internal actions in the structural elements. Although the procedure can be further improved through the introduction of appropriate correction coefficients accounting for the higher modes contribution, it is simple to apply and produces results of sufficient accuracy for the purpose of preliminary design of regular momentresisting frames (characterised by period of vibration lower than $1.5 \mathrm{~s}$ ).

\section{ACKNOWLEDGEMENTS}

Financial supports of Department of Civil Protection (DPC-Reluis 2014-2018 GrantResearch line 6: 'Seismic isolation and dissipation') is gratefully acknowledged.

\section{REFERENCES}

[1] Seismology Committee, Recommended lateral force requirements and commentary, structural engineers association of California, San Francisco, 1974.

[2] CEN, Eurocode 8. Design of structures for earthquake resistance - Part 1: general rules. Seismic Actions and Rules for Buildings, Brussels, 2003.

[3] Norme Tecniche per le Costruzioni, Italian building code, adopted with D.M. 14/01/2008, published on S.O. n. 30 G.U. n. 29 04/02/2008, 2008.

[4] American Society of Civil Engineers ASCE. Minimum design loads for buildings and other structures, ASCE 7-10. Reston, VA, 2010.

[5] Constantinou, M.C. \& Symans, M.D., Seismic response of structures with supplemental damping. Structural Design of Tall Buildings, 2, pp. 77-92, 1993. https://doi.org/10.1002/tal.4320020202

[6] Ramirez, O.M., Constantinou, M.C., Whittaker, A.S., Kircher, C.A. \& Chrysostomou C.Z., Elastic and inelastic seismic response of buildings with damping systems. Earthquake Spectra, 18(3), pp. 531-547, 2002.

https://doi.org/10.1193/1.1509762 
[7] Ramirez, O.M., Constantinou, M.C., Whittaker, A.S., Kircher, C.A., Johnson, M.W. \& Chrysostomou, C.Z., Validation of the 2000 NEHRP provisions' equivalent lateral force and modal analysis procedures for buildings with damping systems. Earthquake Spectra, 19(4), pp. 981-999, 2003.

https://doi.org/10.1193/1.1622392

[8] Whittaker, A.S., Constantinou, M.C., Ramirez, O.M., Johnson, M.W. \& Chrysostomou, C.Z., Equivalent lateral force and modal analysis procedures of the 2000 NEHRP Provisions for buildings with damping systems. Earthquake Spectra, 19(4), pp. 959-980, 2003.

https://doi.org/10.1193/1.1622391

[9] Ramirez, O.M., Constantinou, M.C., Kircher, C.A., Whittaker, A.S., Johnson, M.W., Gomez, J.D. \& Chrysostomou, C.Z., Development and evaluation of simplified procedures for analysis and design of buildings with passive energy dissipation systems. Report MCEER-00-0010, State University of New York, Buffalo, 2001.

[10] Trombetti, T. \& Silvestri, S., On the modal damping ratios of shear-type structures equipped with Rayleigh damping systems. Journal of Sound and Vibration, 292(1), pp. 21-58, 2006.

https://doi.org/10.1016/j.jsv.2005.07.023

[11] Silvestri, S., Gasparini, G. \& Trombetti, T., A five-step procedure for the dimensioning of viscous dampers to be inserted in building structures. Journal of Earthquake Engineering, 14(3), pp. 417-447, 2010.

https://doi.org/10.1080/13632460903093891

[12] Palermo, M., Muscio, S., Silvestri, S., Landi, L. \& Trombetti, T., On the dimensioning of viscous dampers for the mitigation of the earthquake-induced effects in momentresisting frame structures. Bulletin of Earthquake Engineering, 11(6), pp. 2429-2446, 2013. https://doi.org/10.1007/s10518-013-9474-Z

[13] Palermo, M., Silvestri, S., Trombetti, T. \& Landi, L., Force reduction factor for building structures equipped with added viscous dampers. Bulletin of Earthquake Engineering, 11(5), pp. 1661-1681, 2013. https://doi.org/10.1007/s10518-013-9458-Z

[14] Palermo, M., Silvestri, S., Landi, L., Gasparini, G. \& Trombetti, T., Peak velocities estimation for a direct five-step design procedure of inter-storey viscous dampers. Bulletin of Earthquake Engineering, 14(2), pp. 599-619, 2016.

https://doi.org/10.1007/s10518-015-9829-8 